\title{
Thermal stability of polyurethane coating prepared by using diphenylolpropane
}

\author{
(C) Indira N. Bakirova, ${ }^{*+}$ and Svetlana Y. Mitrofanova \\ Kazan National Research Technological University. \\ K. Marx St., 68. Kazan, 420015. Russia.E-mail: bakirova-in@mail.ru
}

$\overline{\text { *Supervising author; }{ }^{+} \text {Corresponding author }}$

Keywords: polyurethane coating, diphenylolpropane, oligooxypropylenetriol, aromatic polyisocyanate, thermooxidative degradation.

Thermal stability of polyurethane varnish coating prepared by using diphenylolpropane, polyetherpolyol and polyisocyanate with an equimolar ratio of isocyanate and hydroxyl groups was assessed in the air. The polyurethane weight loss thermogram shows three temperature regions: I - $(217-275)^{\circ} \mathrm{C}$, II (275-380) ${ }^{\circ} \mathrm{C}$, and III - above $380{ }^{\circ} \mathrm{C}$. For interpreting thermogram of the polyurethane under study the model substances simulating the urethane groups of a polymer were synthesized. The substance containing the urethane group formed by phenolic hydroxyl of diphenylolpropane was shown to demonstrate relatively low thermal stability and gets broken down into isocyanate and bisphenol. Decomposition of the substance containing the urethane group formed by alcoholic hydroxyl occurs at the higher temperature. The data obtained allow interpreting the occurrence of thermal decomposition step I in TGA curve by structural changes in the blocks formed by diphenylolpropane and polyisocyanate being the least stable when exposed to elevated temperatures. The next step can be attributed to decomposition of more thermostable urethane groups formed by functional groups of oligooxypropylenetriol and polyisocyanate. Transition to the step III accompanied by severe sample weight loss due to decomposition of urethane groups is explained by thermal oxidation of oligoether units of polymer. Based on the data obtained the conclusion was made that the presence of urethane groups formed by phenolic hydroxyl of diphenylolpropane in polymer structure results in the decreased thermooxidative decomposition onset temperature of polymer. At the same time, a deceleration of thermooxidative processes due to the stabilizing effect of diphenylolpropane released at the beginning of thermal decomposition of polyurethane is observed in a high-temperature region. The proposed polyurethane coating is inferior to commercial counterparts in thermal decomposition onset temperature but superior to them in the temperature corresponding to a $50 \%$ polymer weight loss.

\section{References}

[1] M.I. Stepanova. Polyurethanes - 2015. Polymer Materials. 2015. No.4. P.8-52. (russian)

[2] Pat. 2393189 Russian Federation

[3] S.E. Mitrofanova, I.N. Bakirova, L.A. Zenitova, A.R. Galimzyanova, E.S. Nefed'ev. Polyurethane varnish materials based on diphenylolpropane. J. Appl. Polymer Sci. 2009. Vol.82. No.9. P.1630-1635.

[4] S.E. Mitrofanova, I.N. Bakirova, O.A. Nikitsova, V.A. Osipova. Swelling ability of polyurethane varnish and paint coatings based on diphenylolpropane. Varnish and Paint Materials and their Application. 2009. No.8. P.20-23. (russian)

[5] S.Y. Mitrofanova, and I.N. Bakirova. Lightfastness of polyurethane coating based on diphenylolpropane. Butlerov Communications. 2018. Vol.55. No.8. P.151-155. DOI: 10.37952/ROI-jbc-01/18-55-8-151

[6] I.N. Bakirova, and S.E. Mitrofanova. Effect of performance parameters on characteristics of polyurethane coating prepared by using diphenylolpropane. Butlerov Communications. 2018. Vol.56. No.11. P.135139. DOI: $10.37952 /$ ROI-jbc-01/18-56-11-135 